\title{
Photocatalytic Degradation of Naphthalene Using Tin Dioxide Nanomaterial under Visible Light
}

\author{
Elvis Fosso-Kankeu*, Dewald de Bruyn, Nthambeleni Mukwevho and Frans Waanders
}

\begin{abstract}
Coal processing in the refinery industry often lead to the formation of coal tar containing polycyclic aromatic hydrocarbons which are likely to affect human and animal health when released in surface and ground waters. A study was conducted to investigate the photocatalytic property of tin dioxide in an attempt to degrade a polycyclic aromatic hydrocarbon namely naphthalene. The tin dioxide nanomaterial was prepared using the sol-gel method and calcination at $500^{\circ} \mathrm{C}$. The synthesised photocatalyst was characterised using techniques such as Fourier Transformed Infra-Red (FTIR) spectroscopy, scanning electron microscopy (SEM) and Energy Dispersive Spectroscopy (EDS) to determine the active groups, the morphology and the elemental composition respectively. The synthesised tin dioxide was then exposed to naphthalene under visible light and the effects of dosage and time on the degradation performance was assessed. The effect of oxidant on the photocatalytic activity of tin dioxide.
\end{abstract}

It was found that $82 \%$ of naphthalene could be removed from the solution using a dosage of $40 \mathrm{mg}$ of $\mathrm{SnO}_{2}$. The degradation of naphthalene could be predicted using Langmuir-Hinshelwood kinetic model resulting in a kinetic rate constant of $0.019 \mathrm{~min}^{-1}$.

Keywords-Tin dioxide, photocatalyst, PAH, coal tar, sol-gel method

\section{INTRODUCTION}

Polyaromatic hydrocarbons (PAHs) are organic chemical compounds, they are a group of compounds which are considered to be toxic. They appear as white, colourless or pale yellow in colour, and their structures are composed of only carbon and hydrogen.

PAHs are lipophilic compounds, their solubility in water will decrease when the molecular weight is increased. Because of the fact that PAHs have hydrophobic properties, they will opt to avoid the water substance and settle at the bottom sedimentation

E. Fosso-Kankeu is with the Water Pollution Monitoring and Remediation Initiatives Research Group and the School of Chemical and Minerals Engineering at the North-West University, Potchefstroom, South Africa.

D. de Bruyn is with the Water Pollution Monitoring and Remediation Initiatives Research Group and the School of Chemical and Minerals Engineering at the North-West University, Potchefstroom, South Africa.

N. Mukwevho is with the Water Pollution Monitoring and Remediation Initiatives Research Group and the School of Chemical and Minerals Engineering at the North-West University, Potchefstroom, South Africa.

F.B. Waanders is with the CoE in Carbon-based fuels and the School of Chemical and Minerals Engineering at the North-West University, Potchefstroom, South Africa
[1]. As a result of the hydrophobic quality, the concentration of these PAHs tends to be high in the sediments of polluted water areas. There is a difference in their physical and chemical characteristics as to the number of aromatic rings as well as the pattern of the ring linkage [2].

PAHs can enter the environment by different means, either through a natural source or an anthropogenic source. PAHs are introduced naturally by means of volcanic reactions or even by field fires. The incomplete combustion of carbon is also one main route for PAHs to enter the environment, together with vehicle exhaust gases, as well as the production of oils, gas and petroleum [1, 3-6]. Tar, produced by the combustion of coal by means of the Fischer array, also contain various forms of PAHs, most notable being Naphthalene. If the specified tar is released into the environment with serious neglect, this could have serious repercussions not only on marine life, but also on the water quality, and possibly contribute to the pollution [7].

Prolonged exposure to various groups of PAHs could lead to a variety of long-term effects. Effects may include; an overall decay of the immune system, kidney and liver damage, asthma-like breathing problems and lung function abnormalities. When a person is exposed for an excessive period to certain PAHs such as naphthalene, it can have a degenerating effect on their health, these PAHs have been classified as carcinogenic, toxic as well as mutagenic to humans. Therefore, most PAHs have been deemed as major pollutants of the environment as well as a threat to humans [2].

Most commonly treated PAHs include naphthalene and anthracene, because of their frequent occurrence. Naphthalene has a white physical appearance and a distinct odour. Naphthalene $\left(\mathrm{C}_{10} \mathrm{H}_{8}\right)$ is detectable in water at concentrations of $0.021 \mathrm{ppm}$ and has a structure of 2 benzene rings. Anthracene enters the environment through the incomplete combustion of coal and is extremely dangerous to marine and wildlife [8]. Water pollution due to industrial activities has been on the increase in South Africa, contributing to the degradation of surface and ground waters [9-19]. The occurrence of any pollutant in the environment must therefore be properly monitor and control using adequate method.

There are various methods that have been introduced to ensure that the PAH concentrations are kept to a minimum. The biodegradation of PAHs is an unfavourable method due to the fact that some PAHs have large molecular weight. These 
specific PAHs will resist the biological process and could even inhibit the process [20].

The photocatalysis is a promising method that can help with the degradation of chemical impurities in water-based substances. Heterogeneous photocatalysis are divided into catalysed and sensitised photoreactions. Semiconductors are energised through light which initialises catalysed photoreactions. The semiconductor is responsible for the transfer of energy to molecules, which are at ground state, and are then absorbed to the surface [21].

Sensitised photoreactions are subject to a molecular reaction that takes place because of the molecules that have been absorbed by the catalyst. These reactions occur while the catalyst is at ground state [22].

Semiconductors such as titanium dioxide $\left(\mathrm{TiO}_{2}\right)$ and zinc oxide $(\mathrm{ZnO})$ have been frequently investigated, however, the potential of tin dioxide for the degradation of PAHs is not well known, hence the need in this study to explore such gap.

\section{MethodOLOGY}

\section{A. Materials}

Ammonium hydroxide $\left(\mathrm{NH}_{4} \mathrm{OH}\right)$ and methanol were all purchased from ACE chemicals with the respective purities being $99.9 \%, 25 \%$ and $99.9 \%$. Tin chloride penta-hydrate $\left(\mathrm{SnCl}_{4} \cdot 5 \mathrm{H}_{2} \mathrm{O}\right)$ was purchased from Sigma and Aldrich with a purity of $99.9 \%$. Naphthalene flakes were utilised for the preparation of the degradable solution.

\section{B. Synthesis of $\mathrm{SnO}_{2}$}

The tin dioxide catalyst was prepared by creating a $0.1 \mathrm{M}$ solution of $\mathrm{SnCl}_{4} \cdot 5 \mathrm{H}_{2} \mathrm{O}$ and methanol. The mixture was continuously stirred for 2 hours at a temperature of approximately $59{ }^{\circ} \mathrm{C}$. During this time, the volume of the mixture decreased significantly. Ammonium hydroxide was added dropwise until the $\mathrm{pH}$ reached a value of 8 , where the liquid mixture now turned to a white-milky gel. Once the gel was obtained, it was placed in an oven to dry, operating at a temperature of $105^{\circ} \mathrm{C}$ for a period of 20 hours. After the gel was dried for the required time, crystals formed, which were crushed before the calcination procedure was done. Calcination of the powders took place in an oxygen environment, ensuring the oxidation and formation of the pure oxide. The furnace was set to a temperature of $500{ }^{\circ} \mathrm{C}$, with calcination only being allowed to occur for 2 hours. Naphthalene solution was prepared by adding 0.1 gram of the naphthalene flakes to a $20 \mathrm{ml}$ mixture of acetic acid. This mixture was stirred until all the flakes were dissolved. Water was added to this mixture, until a total volume of 1000 litre was obtained. This ensured a 100-ppm solution.

\section{Characterisation}

Various characterisation methods were conducted to determine if successful synthesis was achieved, and to determine the purity of the catalysts. The morphology of the catalysts was investigated and evaluated by utilising Scanning Electron Microscopy (SEM). Fourier Transform Infrared Spectroscopy, also known as FTIR Analysis or FTIR Spectroscopy, was used to determine the adsorption affinity and potential of each of the photocatalysts. A Perkin-Elmer Spectrum 100 spectrometer (USA) was used for the FTIR analysis utilising the $\mathrm{KBr}$ pellet method in the spectral range $4000-400 \mathrm{~cm}^{-1}$ with a resolution of $4 \mathrm{~cm}^{-1}$.

\section{Experimental setup}

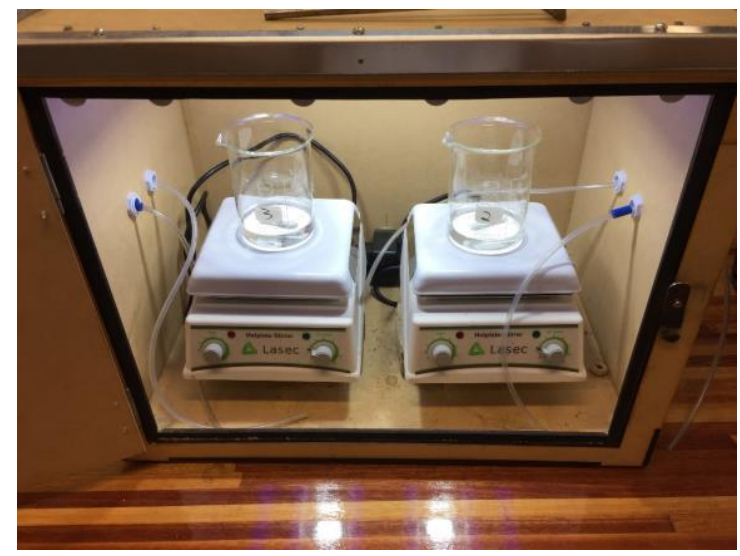

Fig 1: Degradation setup

Fig 1 depicts the degradation setup used during the course of the experiments. One beaker contained the naphthalene solution as well as the desired amount of catalyst, whilst the other only contained only a solution of naphthalene. Another beaker was placed in a dark cupboard as a control, to account for reactions that were occurring in the degradation setup. The first step during the investigation of the degradation experiments was to determine what amount of catalyst preforms the best with only 1 hour of illumination. Prior to the one hour of illumination, the sample was mixed in the dark for 20 minutes before illumination was induced. This was done to ensure that an absorption equilibrium was achieved. After the optimum dosage was obtained, the effect of time was investigated to see to what extent the catalyst could degrade the PAH in solution.

\section{RESULTS AND DISCUSSION}

\section{A. FTIR}

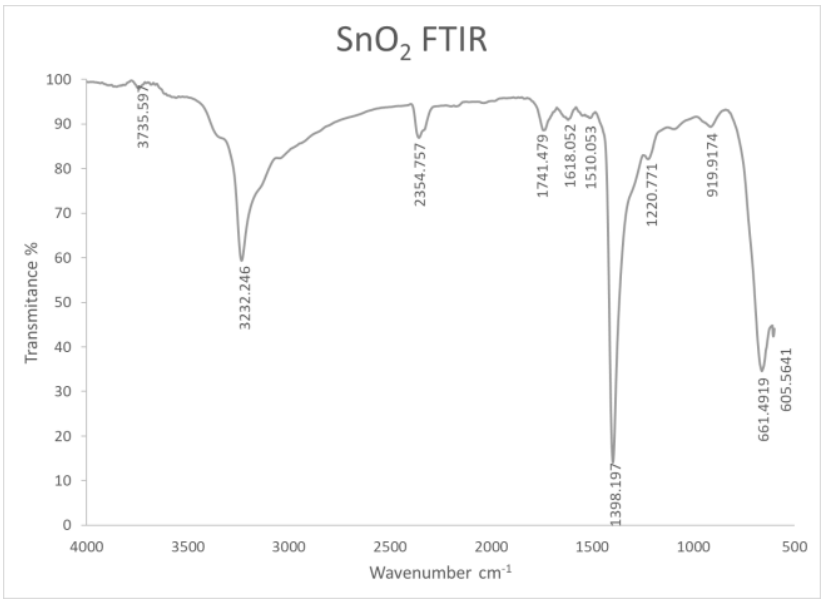

Fig 2: FTIR graph 
It was reported that adsorption peak shifts to a larger wavelength when calcined at higher temperatures. It can thus be said that the peaks observed in Fig 2 at the 605 and $661 \mathrm{~cm}^{-1}$ wavelength can be ascribed to the Sn-O vibration [23]. This once again confirms the successful synthesis of the $\mathrm{SnO}_{2}$ photocatalyst. The peaks seen at the $3232 \mathrm{~cm}^{-1}, 1398 \mathrm{~cm}^{-1}$ and $2354 \mathrm{~cm}^{-1}$ wavelength could be due to $\mathrm{C}-\mathrm{H}$ stretching, described as a strong broad bond. The peak at $1741 \mathrm{~cm}^{-1}$ falls between the bounds of the $\mathrm{C}=\mathrm{O}$ stretch bond. The peak seen at the $1681 \mathrm{~cm}^{-1}$ wavelength can be representing the $\mathrm{N}-\mathrm{H}$ bend bond, which could be due to the use of the $\mathrm{NH}_{4} \mathrm{OH}$ during the synthesis. The $1510 \mathrm{~cm}^{-1}$ peak falls within the range of the $\mathrm{N}-\mathrm{O}$ symmetric stretch, which could also be due to the use of the $\mathrm{NH}_{4} \mathrm{OH}$ during the synthesis process. The peak observed at the $1220 \mathrm{~cm}^{-1}$ wavelength falls within the ranges of the $\mathrm{C}-\mathrm{N}$ stretch bond. The ranges for O-H bend bond ranges from $910-950 \mathrm{~cm}^{-1}$, meaning the peak at $919 \mathrm{~cm}^{-1}$ wavelength forms part of this bond.

\section{B. SEM results}
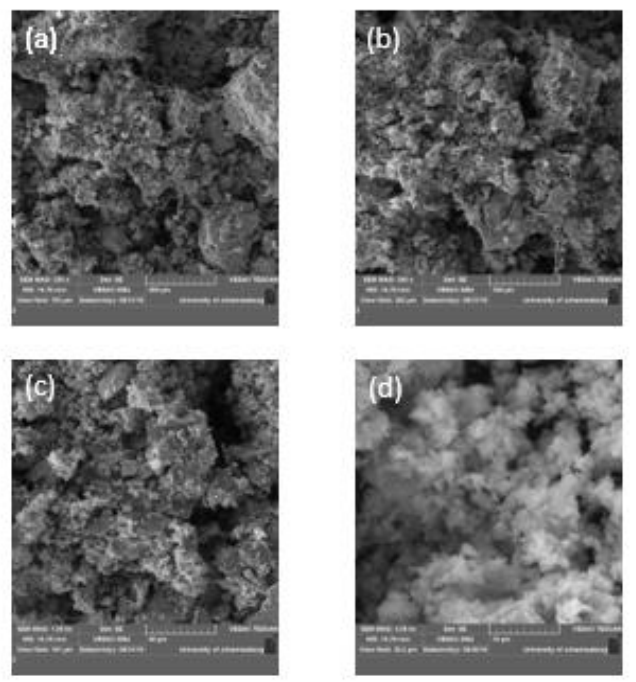

Fig 3: SEM of SnO2 at (a) X250 (b) X500 (c)X1000 and (d) X5000

The various magnifications regarding the $\mathrm{SnO}_{2}$ Nano particles can be seen in Fig 3(a-d). From Figure 3(a) it can be seen that the $\mathrm{SnO}_{2}$ also consist of rather small particles. The morphology of the $\mathrm{SnO}_{2}$ particles are however more evenly distributed than in comparison with that of $\mathrm{ZnO}$ found in literature. The shape of the $\mathrm{SnO}_{2}$ Nano particles is however harder to evaluate. In another study spherical shape particles were reported to be predominant at a magnification of approximately 4000X [24]. When comparing the SEM's of $\mathrm{ZnO}$ from the literature, and Figure 3(d) it is seen that the particles of the $\mathrm{SnO}_{2}$ are smaller, making it more difficult to identify. The smaller particles could also result in better degradation due to a larger surface area contributing to better absorption.

\section{EDS results}

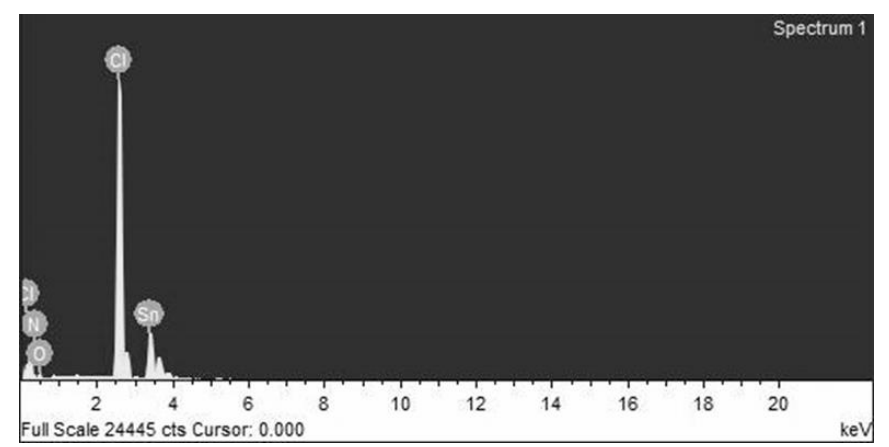

Fig 4: EDS result of $\mathrm{SnO}_{2}$

The EDS analysis of $\mathrm{SnO}_{2}$ can be seen in Fig 4. A large amount of $\mathrm{Cl}$ is present within the catalyst. This could be due to the starting material used, namely tin chloride penta-hydrate. There is however a large amount of Sn within the catalyst, showing that successful synthesis was achieved.

\section{Effect of dosage}

During the degradation experiments, a micro filter was used, which ensured none of the photocatalyst was measured when determining the concentration of the degraded solution. Fig 5 shows the remaining concentration of the naphthalene solution after being in contact with the $\mathrm{SnO}_{2}$ catalyst for approximately one hour. The optimum dosage for the $\mathrm{SnO}_{2}$ was found to be 40 $\mathrm{mg}$, with a removal efficiency of roughly $82 \%$.

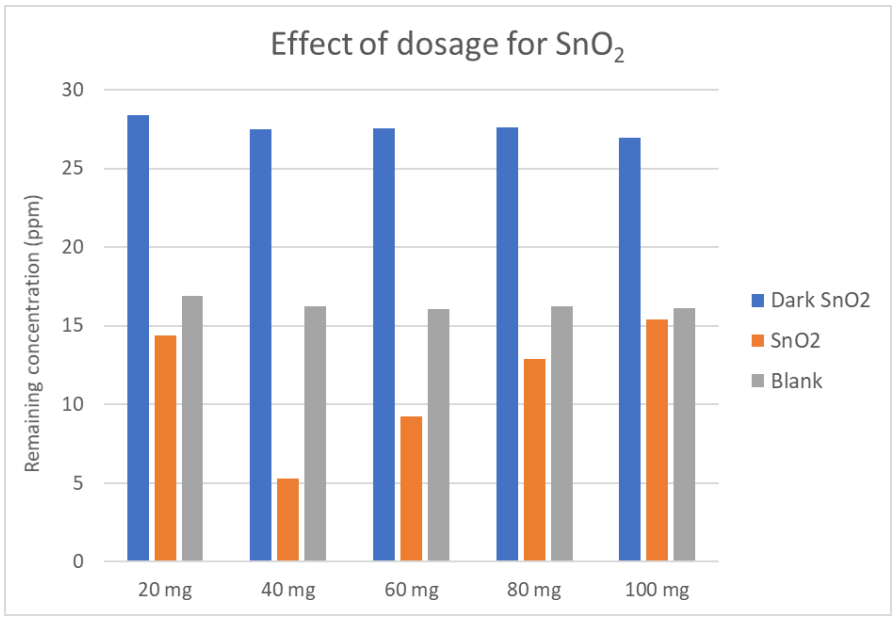

Fig 5: Effect of dosages for $\mathrm{SnO}_{2}$

\section{E. Effect of time}

When evaluating the effect of illumination time, it is clear from Fig 6 that the $\mathrm{SnO}_{2}$ catalyst preceded in degrading the naphthalene solution completely. Various reasons can be ascribed for such behaviour. Taking the SEM results into consideration confirms that such degradation is possible due to the large surface area of the $\mathrm{SnO}_{2}$ catalyst. The final value of the naphthalene concentration was found to be $0.464 \mathrm{ppm}$, resulting in a total removal efficiency of $98 \%$. 


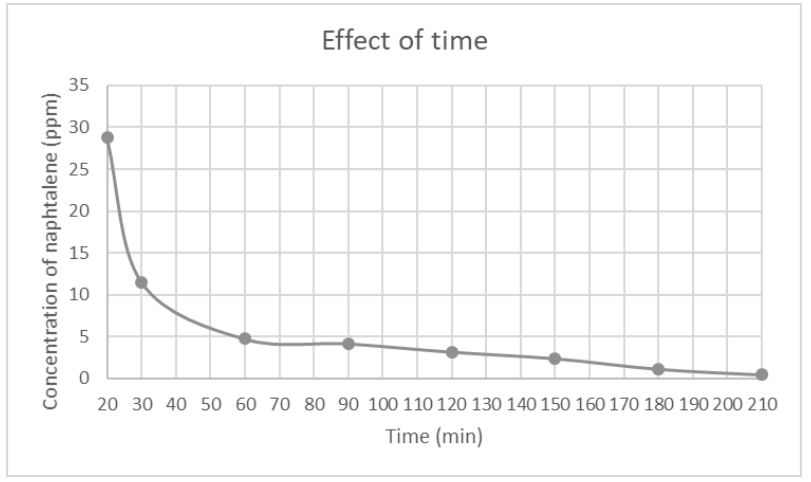

Fig 6: Effect of time

\section{F. Kinetic analysis}

The Langmuir-Hinshelwood kinetic model can be used to determine the reaction rate constants for the degradation of naphthalene. The equations used to describe the reaction rate constants are, as reported by study [25]:

$$
\begin{gathered}
\frac{d C}{d t}=\frac{k \cdot K_{\text {Naphthalene }} \cdot C_{0}}{1+K_{\text {Naphthalene }} \cdot C_{0}} \\
\operatorname{Ln}\left(\frac{C_{0}}{C_{t}}\right)=k \cdot K_{\text {Naphthalene }} \cdot t \\
\operatorname{Ln}\left(\frac{C_{0}}{C_{t}}\right)=K_{\text {app }} \cdot t
\end{gathered}
$$

$K_{\text {Naphthalene }}$ represents the adsorption coefficient regarding the naphthalene onto the three distinct photocatalysts measured in L.mg-1, while $t$ represents the time (min) as the reaction is taking place and $K_{\text {app }}$ is the calculated apparent rate constant measured in $\min ^{-1}$. When considering Fig 7 , there is a noticeable linear relationship, confirming that the kinetic data fits well with pseudo first order kinetics [. Lastly, the degradation of naphthalene with $\mathrm{SnO}_{2}$ catalyst resulted in a $K_{\text {app }}$ value of approximately $0.019 \mathrm{~min}^{-1}$ with a coefficient of determination $\mathrm{R}^{2}$ equal to 0.9294 , indicating a good fit for the trendline [26-31].

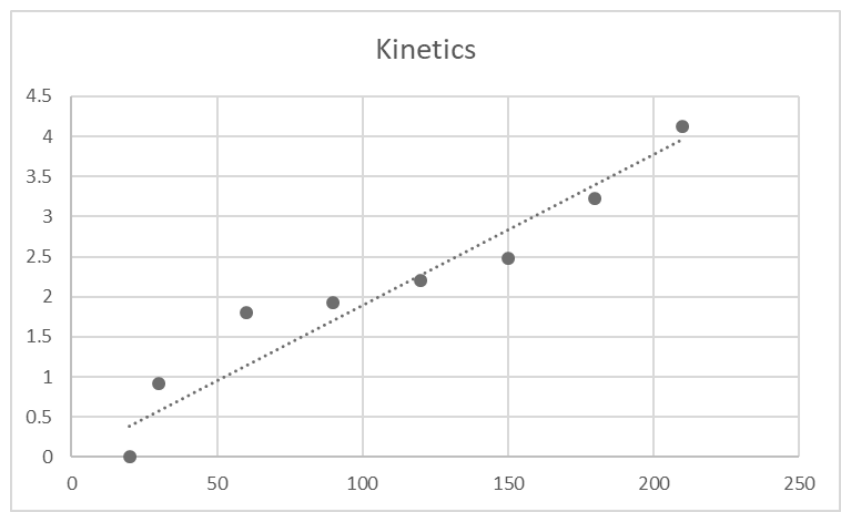

Fig 7: Kinetics of $\mathrm{SnO}_{2}$

\section{CONCLUSION}

In this study it was determined that the synthesis of a photocatalyst referred to as tin dioxide was successful. The method used to synthesise the catalysts is referred to as the sol-gel method where a solid material is produced by using small molecules. Once the sol-gel was obtained, it was calcined at $500{ }^{\circ} \mathrm{C}$, to ensure that the oxide formed. To determine if successful synthesis was achieved, various characterisation techniques were used such as SEM, EDS as well as FTIR. From this, the various functional groups could be determined, the morphology could be evaluated, and the presence of various elements could be determined. In the FTIR analyses it was evident that an oxide was formed due to the peaks observed between $650 \mathrm{~cm}^{-1}$ and $900 \mathrm{~cm}^{-1}$ confirming successful synthesis of a $\mathrm{SnO}_{2}$ catalyst. This was also confirmed by the EDS analyses. In the SEM analyses it was found that the $\mathrm{SnO}_{2}$ had large surface area, theoretically contributing to good degradation potential. The optimum dosages for the catalyst were determined to ensure that an excess of catalyst was not used during the effect of time experiments. The optimum dosages for the catalyst was found to be $40 \mathrm{mg}$ of $\mathrm{SnO}_{2}$. The effect of illumination time was used to determine the kinetic of the degradation of the naphthalene in solution. It was found that the $\mathrm{SnO}_{2}$ catalyst almost completely degraded the naphthalene in solution after 3 and a half hours of illumination time with an overall removal efficiency of $98 \%$.

\section{ACKNOWLEDGMENT}

DC de Bruyn is extremely grateful for the patience, leadership as well as the leadership provided by Prof. E. Fosso-Kankeu, he is a remarkable study leader, a great leader and certainly a great mentor. The authors acknowledge the assistance of Dr Neeraj Kumar from CSIR.References

\section{REFERENCES}

[1] Keshavarzifard, M., et al. (2016). "Evaluation of polycyclic aromatic hydrocarbons contamination in the sediments of the Johor Strait, Peninsular Malaysia." Polycyclic Aromatic Compounds: 1-16. https://doi.org/10.1080/10406638.2016.1257997

[2] Kafilzadeh, F. (2015). "Distribution and sources of polycyclic aromatic hydrocarbons in water and sediments of the Soltan Abad River, Iran." The Egyptian Journal of Aquatic Research 41(3): 227-231. https://doi.org/10.1016/j.ejar.2015.06.004

[3] N. Mukwevho, E. Fosso-Kankeu, F. Waanders, G. Gericke, J. Bunt, Synthesis and characterization of $\mathrm{ZnO}$ nanoparticle and application in the photodegradation of organic pollutants in effluents from coal power station. International Conference on Advances in Science, Engineering, Technology and Natural Resources (ICASETNR-16) Nov. 24-25, 2016, Parys - South Africa. ISBN: 978-93-84468-79-8. 2016.

[4] N. Mukwevho, E. Fosso-Kankeu, F. Waanders, N. Kumar, S.S. Ray, Synthesis and properties of $\mathrm{ZnO} / \mathrm{Ag} / g r a p h e n e$ oxide composites photocatalyst. $9^{\text {th }}$ Int'l Conference on Advances in Science, Engineering, Technology \& Waste Management (ASETWM-17). 27-28 November 2017, Parys, South Africa. Editors: F. Waanders, E. Fosso-Kankeu, B. Topcuoglu, M. Plaisent, Y. Thaweesak. ISBN: 978-81-934174-6-1. Pp. 49-52. 2017.

[5] T.C. Khethane, E. Fosso-Kankeu, F. Waanders, J. Bunt, PAHs content of tar produced from Fischer assay of medium rank $\mathrm{C}$ bituminous South African coal. $9^{\text {th }}$ Int'l Conference on Advances in Science, Engineering, Technology \& Waste Management (ASETWM-17). 27-28 November 
2017, Parys, South Africa. Editors: F. Waanders, E. Fosso-Kankeu, B. Topcuoglu, M. Plaisent, Y. Thaweesak. ISBN: 978-81-934174-6-1. Pp. 161-164. 2017.

[6] N. Mukwevho, E. Fosso-Kankeu, F. Waanders, N. Kumar, S.S. Ray, X.Y. Mbianda, Evaluation of the photocatalytic activity of $\mathrm{Gd}_{2} \mathrm{O}_{2} \mathrm{CO}_{3} . \mathrm{ZnO}$. CuO nanocomposite used for the degradation of phenanthrene. Springer Nature Applied Sciences. 2018.

[7] Vulava, V. M., et al. (2017). "Flood-induced transport of PAHs from streambed coal tar deposits." Science of the Total Environment 575: 247-257.

https://doi.org/10.1016/j.scitotenv.2016.09.222

[8] Singh, P., et al. (2013). "Reusable electrospun mesoporous $\mathrm{ZnO}$ nanofiber mats for photocatalytic degradation of polycyclic aromatic hydrocarbon dyes in wastewater." Journal of colloid and interface science 394: 208-215.

https://doi.org/10.1016/j.jcis.2012.12.006

[9] E. Fosso-Kankeu, P. Jagals, H. Du Preez, Exposure of rural households to toxic cyanobacteria in container-stored water. Water SA, Vol. 34, no. 5 , pp. 631-636, 2008

[10] E. Fosso-Kankeu, A. Mulaba-Bafubiandi, B.B. Mamba, T.G. Barnard, Mitigation of $\mathrm{Ca}, \mathrm{Fe}$, and $\mathrm{Mg}$ loads in surface waters around mining areas using indigenous microorganism strains. Journal of Physics and Chemistry of the Earth, Vol. 34, pp. 825-829, 2009.

https://doi.org/10.1016/j.pce.2009.07.005

[11] E. Fosso-Kankeu, H. Du Preez, P. Jagals, The health implication of relationships between bacterial endotoxin, cyanobacteria, coliforms and water stored in domestic containers of rural households in South Africa. Journal of Water and Health, Vol. 8, no. 4, pp. 601-610, 2010. https://doi.org/10.2166/wh.2010.094

[12] E. Fosso-Kankeu, A. Mulaba-Bafubiandi, B.B. Mamba, L. Marjanovic, T.G. Barnard, A comprehensive study of physical and physiological parameters that affect biosorption of metal pollutants from aqueous solutions. Journal of Physics and Chemistry of the Earth, Vol. 35, pp. 672-678, 2010. https://doi.org/10.1016/j.pce.2010.07.008

[13] E. Fosso-Kankeu, A. Mulaba-Bafubiandi, B.B. Mamba, T.G. Barnard, Assessing the effectiveness of a biological recovery of nickel from tailings dumps. Journal of Minerals Engineering. Vol. 24, pp. 470-472, 2011 https://doi.org/10.1016/j.mineng.2010.11.007

[14] E. Fosso-Kankeu, A.F. Mulaba-Bafubiandi, B.B. Mamba and T.G. Barnard, Prediction of metal-adsorption behaviour in the remediation of water contamination using indigenous microorganisms. Journal of Environmental Management. Vol. 92, no. 10, pp. 2786-2793, 2011 https://doi.org/10.1016/j.jenvman.2011.06.025

[15] H. Mittal, E. Fosso-Kankeu, Shivani B. Mishra, Ajay K. Mishra, Biosorption potential of Gum ghatti-g-poly (acrylic acid) and susceptibility to biodegradation by B. subtilis. International Journal of Biological Macromolecules. Vol. 62, pp. 370-378, 2013. https://doi.org/10.1016/j.ijbiomac.2013.09.023

[16] E. Fosso-Kankeu, A.F. Mulaba-Bafubiandi, T.G. Barnard, Establishing suitable conditions for metals recovery from metal saturated Bacillaceae bacterium using experimental design. International Biodeterioration and Biodegradation. Vol. 86, pp. 218-224, 2014. https://doi.org/10.1016/j.ibiod.2013.09.022

[17] E. Fosso-Kankeu, A.F. Mulaba-Bafubiandi, Implication of plants and microbial metalloproteins in the bioremediation of polluted waters. Journal of Physics and Chemistry of the Earth. Vol. 67-69, 242-252, 2014. https://doi.org/10.1016/j.pce.2013.09.018

[18] E. Fosso-Kankeu, A.F. Mulaba-Bafubiandi, Challenges in the escalation of metal-biosorbing processes for water treatment: applied and commercialized technologies. African Journal of Biotechnology. Vol. 13, no. 17 , pp. 1756-1771, 2014. https://doi.org/10.5897/AJB2013.13311

[19] E. Fosso-Kankeu, H. Mittal, S.B. Mishra, A.K. Mishra, Gum ghatti and acrylic acid based biodegradable hydrogels for the effective adsorption of cationic dyes. Journal of Industrial and Engineering Chemistry. Vol. 22, pp. 171-178, 2015

https://doi.org/10.1016/j.jiec.2014.07.007
[20] Haritash, A. and C. Kaushik (2009). "Biodegradation aspects of polycyclic aromatic hydrocarbons (PAHs): a review." Journal of hazardous materials 169(1-3): 1-15. https://doi.org/10.1016/j.jhazmat.2009.03.137

[21] Nischk, M., et al. (2014). "Ordered TiO2 nanotubes: The effect of preparation parameters on the photocatalytic activity in air purification process." Applied Catalysis B: Environmental 144: 674-685. https://doi.org/10.1016/j.apcatb.2013.07.041

[22] Bahnemann, D., et al. (1984). "Detection of the intermediates of colloidal TiO 2-catalysed photoreactions." Faraday Discussions of the Chemical Society 78: 151-163. https://doi.org/10.1039/dc9847800151

[23] Chang, S.-T., et al. (2002). "Preparation and characterization of nanostructured tin oxide films by electrochemical deposition." Electrochemical and solid-state letters 5(8): C71-C74. https://doi.org/10.1149/1.1485808

[24] Vignesh, K., et al. (2013). "Photocatalytic performance of Ag doped $\mathrm{SnO} 2$ nanoparticles modified with curcumin." Solid State Sciences 21: 91-99.

https://doi.org/10.1016/j.solidstatesciences.2013.04.017

[25] Kumar, K. V., et al. (2008). "Langmuir-Hinshelwood kinetics - A theoretical study." Catalysis Communications 9(1): 82-84. https://doi.org/10.1016/j.catcom.2007.05.019

[26] E. Fosso-Kankeu, H. Mittal, F. Waanders, I.O. Ntwampe, S.S. Ray, Preparation and characterization of gum karaya hydrogel nanocomposite flocculant for metal ions removal from mine effluents. International Journal of Environmental Science and Technology. Vol. 13, pp. 711-724, 2016. https://doi.org/10.1007/s13762-015-0915-x

[27] E. Fosso-Kankeu, F. Waanders, E. Maloy, Copolymerization of ethyl acrylate onto guar gum for the adsorption of $\mathrm{Mg}$ (II) and $\mathrm{Ca}$ (II) ions. Desalination and Water Treatment. doi: 10.1080/19443994.2016.1165147: pp. 1-10, 2016 https://doi.org/10.1080/19443994.2016.1165147

[28] E. Fosso-Kankeu, F. Waanders, C.L. Fourie, Adsorption of Congo Red by surfactant-impregnated bentonite clay. Desalination and Water Treatment. doi: 10.1080/19443994.2016.1177599: pp. 1-9, 2016 https://doi.org/10.1080/19443994.2016.1177599

[29] E. Fosso-Kankeu, H. Mittal, F. Waanders, S.S. Ray, Thermodynamic properties and adsorption behaviour of hydrogel nanocomposites for cadmium removal from mine effluents. Journal of Industrial and Engineering Chemistry. Vol. 48, pp. 151-161, 2017 https://doi.org/10.1016/j.jiec.2016.12.033

[30] E. Fosso-Kankeu, F.B. Waanders, F.W. Steyn, Removal of $\mathrm{Cr}(\mathrm{VI})$ and $\mathrm{Zn}$ (II) from an aqueous solution using an organic-inorganic composite of bentonite-biochar-hematite. Desalination and Water Treatment. Vol. 59, pp. 144-153, 2017

[31] A. Leudjo Taka, E. Fosso-Kankeu, K. Pillay, X. Yangkou Mbianda, Removal of cobalt and lead ions from wastewater samples using an insoluble nanosponge biopolymer composite: Adsorption isotherms, kinetics, thermodynamics and regeneration studies. Environmental Science and Pollution Research. 2018. 